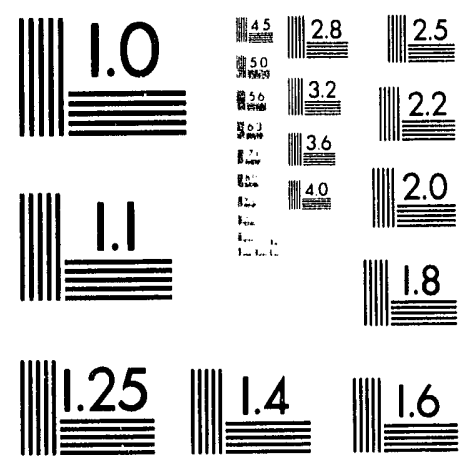



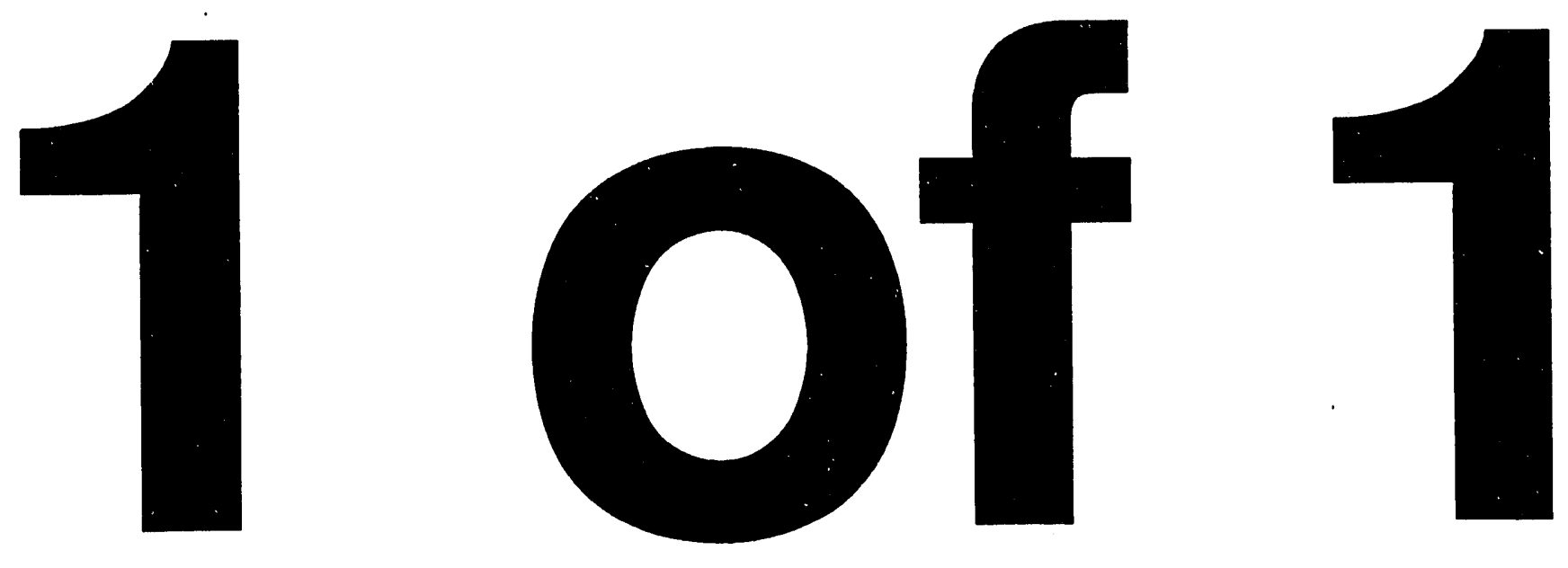


\title{
Role of Neutral-Beam Fueling Profile in Energy Confinement and Neutron Emission on TFTR
}

\author{
H.K. Park, M.G. Bell, W.M. Tang, G. Taylor, M. Yamada, \\ R.V. Budny, D.C. McCune, R. Wieland \\ Princeton Plasma Physics Laboratory \\ Princet on University \\ P. O. Box 451 Princeton, NJ 08543
}

\begin{abstract}
The role of the neutral-beam fueling profile in determining the stored energy and neutron emission in neutral-beam heated discharges on TFTR is investigated. It is found that the neutral-beam fueling profile is sensitive to both the magnitude and shape of the electron density. Among the plasma species, the ion stored energy is strongly correlated with the peaking of the neutral-beam fueling profile, whereas the electron stored energy is insensitive to this parameter. The D-D fusion neutron emission is also strongly correlated with the peaking of the neutral-beam fueling profile.
\end{abstract}

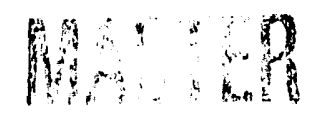




\section{Introduction}

In intense $\left(P_{B} \gg P_{O H}\right)$ neutral-beam-heated plasmas in the Tokamak Fusion Test Reactor $(\mathrm{TF} T \mathrm{R})$, the global energy confinement time $\left(\tau_{E}\right)$ ranges from $\simeq 50 \mathrm{~ms}$ to $\simeq 200 \mathrm{~ms}$. The discharges with low $\tau_{E}$ are often referred to as $\mathrm{L}$-mode and fit to the empirical L-mode scaling.|1] Although the characteristics of $\tau_{E}$ in the L-mode regime are well described by the empirical L-mode scaling relationship, $[1,2]$ the basic physics underlying these scalings is largely unknown. Discharges with an improved energy confinement with respect to the L-mode confinement (TFTR "supershot"[3] discharges) do not follow the L-mode scaling and their $\tau_{E}$ is only weakly dependent on plasma current and heating power. A distinctive peaked electron density profile shape [4] and high ion temperature are major characteristics of supershot discharges. $[5,6]$

With respect to other measurable plasma parameters that can be correlated with the improved energy confinement and neutron emission, this paper in particular examines the role of the neutral-beam fueling profile on the stored energy and DD fusion neutron emission. In section II, the neutral-beam fueling profile is studied as a function of target electron density profile shape and magnitude. In section III,

a general description of the data set to be studied is given. The constraints on the data set and their statististical implications are also discussed. In section IV, the role of the neutral-beam fueling profile in determining the stored energy of each plasma speries (ions and electrons) and the D-D fusion neutron emission is investigated.

\section{Neutral-beam Fueling Deposition}

Following the recent study of the neutral-beam particle deposition in TFTR, [7] the calculated neutral-beam particle deposition profile shape factor $\left(H_{n e}\right)$ is defined as

$$
H_{n e}=\frac{S_{b e}(0, t)}{\left\langle S_{b e}(r, t)\right\rangle},
$$


where $S_{b e}(0, t)$ and $\left\langle S_{b e}(r, t)\right\rangle$ are the central and volume-averaged electron source rates due to the neutral-beam, respectively. This definition is similar to the density peakedness factor $F_{n e}=n_{e}(0) /\left\langle n_{e}\right\rangle$, where $n_{e}(0)$ is the central electron density and $\left\langle n_{e}\right\rangle$ is volume-averaged electron density. In reference [7], it was shown that the calculation of the neutral-beam deposition in a tokamak plasma should employ both the new tabulation of atomic cross-sections [8] and Multi-Step Ionization (MSI) processes.[9] The attenuation of the injected neutral-beam is to first order proportional to the local electron density, so a peaked neutral-beam deposition profile can only be achieved at high density with a peaked density profile. In order to parameterize the expression for $H_{n e}$ for a variety of $F_{\text {re }}$, a regression has been performed for values of $H_{\text {ne }}$ calculated by the TRANSP code[10] as a function of $\bar{n}_{e}$ and $F_{n e}$. The range of $F_{n e}$ of this data set is from 0.5 to 5.0 (see reference [7]). A mong the functional combinations, the best description is as follow:

$$
H_{n e} \simeq \alpha F_{n e}^{\beta} \exp \left[-\gamma \bar{n}_{e}\right\rfloor
$$

where $\alpha, \beta$ and $\gamma$ are regression coefficients appropriate to the TFTR data base. The calculated $H_{n e}$ using old atomic cross-sections $\left(\sigma_{1}\right)$, or $\sigma_{1}$ and MSI processes and new atomic cross-sections $\left(\sigma_{2}\right)$ has been fitted to Eq. 2. The regression coefficients are shown in Table 1.

\begin{tabular}{|c|c|c|c|c|}
\hline cross - section & symbol & $\alpha$ & $\beta$ & $\gamma$ \\
\hline$\sigma_{1}$ & $\circ$ & 2.41 & 1.04 & $0.24 \times 10^{-19}$ \\
$\sigma_{1}+M S I$ & $\triangle$ & 2.86 & 1.07 & $0.33 \times 10^{-19}$ \\
$\sigma_{2}$ & $\square$ & 2.49 & 0.90 & $0.18 \times 10^{-19}$ \\
\hline
\end{tabular}

Table 1: Coefficients for $H_{n e}$ are evaluated using various cross-sections: $\sigma_{1}$ uses the old tabulation of atomic cross-sections, $\sigma_{2}$ uses the new tabulation of atomic crosssections, and $\sigma_{1}+\mathrm{MSI}$ uses the old cross-section plus MSI model

The ratio of the calculated $H_{n e}$ to the fitted $H_{n e}$ is illustrated as a function of $\bar{n}_{e}$ in Fig. 1. The relationship in Eq.(2) shows that a peaked electron density profile 
shape is essential for peaked deposition of the neutral-beam at high density. Since the calculation with both $\sigma_{2}$ and MSI processes is not available, the coefficients evaluated using only $\sigma_{1}$ will be used in the regression study (see reference [7]).

Note that $H_{n e}$ is different from the conventional neutral-beam power deposition peaking factor $(H(0)$, where $H(0)$ is defined as the ratio of the central neutral-beam power per unit volume to the volume averaged power) due to the presence of fractional energy components $(E / 2$, and $E / 3)$ in the heating-beam. If the beam has only a full energy component, $H_{n e}$ is the same as $H(0)$. In addition to the magnitude and profile shape of the electron density, there are many other machine parameters which can influence $H_{n e}$ such as beam energy, angle of injection, beam size, plasma size (major and minor radius) and plasma cross-sectional shape (circular or non-circular). Therefore, this parameter should be determined considering these engineering and physical parameters for each experiment. For example, at the same line average density, a non-circular plasma $(\kappa \geq 1)$ will have higher $H_{n e}$ than a circular plasma due to the volume effect.

Using the measured $F_{n e}(t)$ and $\bar{n}_{e}(t)$, it is instructive to examine the time dependence of $H_{n e}$ together with other plasma parameters for typical TFTR discharges. Fig. 2 show's the temporal evolution of $H_{n e}$ for L-mode and supershot discharges for the same beam power $\left(P_{B} \simeq 22 \mathrm{MW}\right)$. In the supershot, the initial central beam fueling is significantly better compared to the L-mode due to differences in the prebeam electron density. The initial high level of central beam fueling is maintained $\left(H_{n e} \simeq 3.0\right)$ as $\bar{n}_{e}$ is increased, until a "Carbon bloom"[11] (accompanied by a sudden rise of edge electron density) occurs at about $3.8 \mathrm{sec}$. The degradation of $W_{\text {tot }}$ and neutron emission $\left(S_{n}\right)$ is well correlated with the reduction in $H_{n e}(\simeq 3.0$ to $\simeq 1.0)$. For the L-mode plasma, the low initial beam fueling $\left(H_{n e} \simeq 1.0\right)$ falls rapidly to $\simeq 0.3$ so that after that time of NBI, there is almost an order of magnitude difference in $H_{n e}$ between the supershot and L-mode plasmas. It is striking, however, that the accumulated $W_{e}$ in each discharge is similar in magnitude. This result implies that $W_{i}$ 
in the supershot discharge is significantly greater than that of the L-mode discharge. The D-D fusion neutron emission in the L-mode discharge is an order of magnitude smaller than that of the supershot discharge.

\section{Data base and Constraints}

This study involves approximately 870 TFTR deuterium discharges, constrained to deuterium gas fueled discharges only. The data points consist of each plasma parameter at the peak time of the global stored energy. Wide range of beam power $\left(5 \leq P_{B} \leq 32 M W^{\prime}\right)$ and plasma current $\left(0.9 M A \leq I_{P} \leq 2.0 M A\right)$ are included. Here, discharges with plasma current ramps during the heating pulse are excluded. In all discharges, the beam power exceeds the Ohmic power by a factor of $\geq 5$ to reduce the influence of Ohmic heating on the confinement. Deuterium beams with $90 \mathrm{keV} \leq E_{i n j} \leq 110 \mathrm{keV}$ are injected tangentially and data are restricted to nearly balanced injection, i.e., $\left|\left(P_{c o}-P_{c t r}\right) /\left(P_{c o}+P_{c t r}\right)\right| \leq 0.4$, where the subscript co and $c t r$ refer to injection in the same and opposite direction with respect to the plasma current, respectively. The neutral particle ratio used in this paper is $D^{0}[E]: D^{0}[E / 2]: D^{0}[E / 3]=0.44: 0.30: 0.26$. The total stored energy $\left(W_{t o t}^{\prime}\right)$ is determined from magnetic measurements, $[12]$ so that both the thermal and fast-beam ion energies are included. The electron stored energy $\left(W_{e}\right)$ is calculated[4] using the inverted electron density profile[13] measured by multi-channel interferometry[14] and the electron temperature profile measured by ECE radiometry.[15] The ion stored energ. $\left(W_{i}\right)$ is simply $W_{\text {tot }}-W_{\mathbf{e}}$.

In a statistical study, it is important to isolate the inter-correlation between the assumed independent parameters. In order to eliminate other possible strong parametric dependences, this data set is constrained to fixed plasma major and minor radii of $\mathrm{R}=2.45 \mathrm{~m}$, and $\mathrm{a}=0.8 \mathrm{~m}$. The toroidal magnetic field is $B_{T}=4.0 \mathrm{~T}$ and 4.8 T. $B_{T}$ and $E_{i n j}$ can be used as independent parameters but their variation is too small to show explicit dependences. There are many other plasma parameters that can be 
correlated with the performance of discharges such as the pre-beam electron density and carbon intensity which can be a measure of the wall recycling condition. It is expected that $H_{n e}$ is well correlated with the condition of the wall recycling. $H_{n e}$ will be added as an independent parameter in addion to $I_{P}$, and $P_{B}$. These parameters are not completely independent due to the operational constraints in experiments. However, with the inclusion of L-mode data, the inter-correlations between these parameters are minimized. For instance, the upper limit of $P_{B}$ can be raised as $I_{P}$ is increased due to the $\beta$-limit as shown in Fig. 3a. Similarly, the achieved upper limit of $H_{n e}$ is reduced as $l_{F}$ is increased as shown in Fig. 3b. The upper limit of $H_{n e}$ is slightly reduced as $P_{B}$ is increased as shown in Fig. 3c.

As shown in the previous section for a fixed plasma geometry, $H_{n e}$ is sensitive only to the electron density and its profile shape. Therefore the reduced upper limit of $H_{n e}$ at higher $I_{F}$, must be interpreted as the higher electron density and/or broader profile shape. It is important to know whether the increased electron density at higher applied plasma current is due to the improved particle confinement time or increased wall recycling for a carbon limiter. Since similar wall conditioning techniques have been applied for the carbon limiter, it seems likely that the improved intrinsic particle confinement time at higher $I_{P}$ may be responsible for the increased electron density. Note that the pre-beam and edge electron density can be lowered at higher plasma current using lithium pellets in TFTR.[16]

\section{Role of $H_{n e}$ on Stored Energy and Neutron Emission}

Although several regimes of enhanced energy confinement relative to the L-mode predictions have been produced in TFTR, $[5,6]$ we will concentrate in this section on the role of $H_{n e}$ in the variation of energy confinement and D-D fusion neutron emission from L-mode to supershots.

Among other distinctive characteristics, the performance of the beam-heated dis- 
charge has been strongly correlated with the peakedness of the electron density profile[4]. Although There has been an attempt to interpret the observed correlation with the transport physics associated with the density gradient, the results were not conclusive[17]. This is due in large part to the fact that the physics of the time evolution of these discharges is extremely complicated as a result of the rapid simultaneous changes of many plasma parameters and their profiles. It is important to note that a peaked electron density profile alone is not a sufficient condition to improve stored plasma energy in beam heated discharges in TFTR. When high density ohmically heated target plasmas, fueled with solid deuterium pellets were heated with bearns, the resulting stored energy was generally similar to L-mode discharges, even though the electron density profiles were highly peaked. This observation leads to the conclusion that the peakedness of the electron density profile is not sufficient to improve the confinement and that the observed peaked electron density profile in the supershot discharge may be due to different causes. When $H_{n e}$ was evaluated for the discharges, the value was found to be very low (in general $H_{n e} \leq 1.5$ ). When $H_{n e}$ was high $(\geq 3.0)$ for these discharges, the stored energy and neutron emission were significantly improved over that of L-mode discharges. We are led to the hypothesis that the observed correlation between the improved energy confinement and peaking of the density profile may originate from the fact that central penetration of the beam can only be achieved with a peaked density profile at high density and the peaked electron density profile will result from the peaked beam deposition.

Considering the observed high central ion temperature and low central impurity level in a good supershot plasma, the improved global energy confinement is largely due to the ions rather than electrons as shown in Fig. 4. Here, the fraction of stored energy of the ions is depicted as a function of central beam fueling parameter, $P_{B} H_{n e}$. Up to $P_{B} H_{n e} \simeq 25 \mathrm{MW}$, the ion fraction increases rapidly and the ratio saturates at about $\simeq 0.7$. Note that $W_{i}$ consists of both thermal and fast beam-ions. In principle, the stored energy of fast-beam ions should be studied separately from thermal ions 
to determine if there are differences in their confinement properties. Since, there are practical problems such as precise information regarding local ion density and slowing down time at high ion temperature, the ion stored energy will not be treated separately in this paper.

The variation of ion stored energy is illustrated as a function of $P_{B}$ in Fig. 5a. It will be shown that the observed variation can be significantly reduced by additional parameters $\left(H_{n e}\right.$, and $\left.I_{P}\right)$. Most importantly, the role of $H_{n e}$ is more significant than that of $I_{P}$. The regression result of the ion stored energy shows that the the goodness of fit $\left(R^{2}\right)$ is 0.95 and is given in the below;

$$
W_{i}(M J) \simeq C P_{B}^{1.21 \pm 0.01}(M W) H_{n e}^{0.90 \pm 0.01} I_{P}^{0.38 \pm 0.02}(M A)
$$

where $C$ is $2.14 \times 10^{-2}$. Note that the plasma parameters used in this study are at the peak time of $W_{t o t}$. When the regression was performed without $I_{P}$, the $R^{2}$ value was 0.93 with slightly' different coefficients $\left(W_{i}^{\prime} \propto P_{B}^{1.30} H_{n e}^{0.81}\right)$. This result indicates that the role of $H_{n e}$ is significantly more important than that of $I_{P}$ in determining the ion stored energy. In order to demonstrate the significance of $H_{n e}$, a similar regression is performed for $W_{i}$ with $P_{B}$ and $H_{n e}$ as independent parameters at a fixed $I_{P}$ group. The regression coefficients and goodness of fit $\left(R^{2}\right)$ for $W_{i} \propto P_{B}^{\alpha \pm \Delta \alpha} H_{n e}^{\beta \pm \Delta \beta}$ are summarized in Table 2. The results demonstrated in Fig. 5b and Table 2, lead

\begin{tabular}{|c|c|c|c|c|c|c|}
\hline Plasma Current & Data Points & $R^{2}$ & $\alpha$ & $\Delta \alpha$ & $\beta$ & $\Delta \beta$ \\
\hline$I_{P}=0.9 / 1.0 \mathrm{MA}$ & 276 & 0.93 & 1.19 & \pm 0.04 & 1.04 & \pm 0.02 \\
$I_{P}=1.4 / 1.6 \mathrm{MA}$ & 364 & 0.95 & 1.26 & \pm 0.02 & 0.88 & \pm 0.01 \\
$I_{P}=1.8 / 2.0 \mathrm{MA}$ & 228 & 0.97 & 1.19 & \pm 0.01 & 0.79 & \pm 0.02 \\
\hline
\end{tabular}

Table 2: Coefficients of the regression results are evaluated for each plasma current group. The role of $H_{\text {ne }}$ on the ion stored energy is not altered by an absence of $I_{P}$. $W_{i} \propto P_{B}^{\alpha \pm \Delta \alpha} H_{n e}^{\beta \pm \Delta \beta}$ is used for each $I_{P}$ group.

to the conclusion that the central beam fueling $\left(P_{B} H_{n e}\right)$ is strongly correlated the observed ion stored energy for any plasma current. 
On the other hand, the electron stored energy is not as well correlated $\left(R^{2}\right.$ with the same set of independent parameters and the result is given as;

$$
W_{e}(M J) \simeq C P_{B}^{0.68: \pm 0.02} I_{p}^{0.47 \pm 0.03} H_{r e}^{0.12 \pm 0.01}
$$

where $C$ is $7.6 \times 10^{-2}$. It is surprising that the parameteric dependence of electron stored energy' is significantly different from that of ions. When the regression was performed without $H_{n e}, R^{2}$ was reduced from 0.8 to 0.77 and $W_{c} \propto P_{B}^{0.68} I_{P}^{0.37}$. Certainly $H_{n e}$ was important in determination of ion energy but not important at all in electron stored energy.

Due to the dominance of the ion stored energy in supershots, any global scalings for the energy confinement simply represent the trend of ion confinement and have little to do with the nature of electron confinement. If $H_{n e}$ is assumed to be propotional to the power deposition peaking factor $(H(0))$, the exisisting theoretical model for the influence of $H(0)$ on the global stored energy $|18|$, which is based on a single fluid model may not be suitable for beam-heated plasmas.

In fusion plasma studies, the ultimate goal is the production of fusion power which is proportional to the neutron emission rate $\left(S_{n}\right)$. In TFTR, $S_{n}$ from D-D reactions has been strongly correlated with the square of the total stored energy $\left(\propto W_{\text {tot }}^{2}\right)|5|$ and the upper bound of $S_{n}$ has been scaled with the beam power $\left(\propto P_{B}^{1.8}\right)|20,21|$. Based on the results in Eqs. 3 and 4, the two scalings must be closely related through the ion stored energy. Using the same set of independent parameters employed in the study of energy confinement, a regression is performed for $S_{n}$ and the result is given as follow;

$$
S_{n}(/ \text { sec. }) \sim C P_{B}^{2.09+0.02}(M W) H_{n e}^{1.40+50.02} I_{P}^{0.31+0.04}(M A),
$$

where $C$ is $1.00 \times 10^{13}$ and $R^{2}$ is 0.96 . The fitted data to this result is shown in Fig. 6 and the neutron emission is dominated by $P_{B}$ and $H_{n e}$. When the same regression was performed without including the plasma current, $R^{2}$ was reduce from 0.96 to 0.95 with slightly different coefficients $\left(S_{n} \propto P_{H}^{2.19} H_{n e}^{1.34}\right)$. Similar to the ion stored 
energy case, the significance of $H_{n e}$ is examined for each of the plasma current groups and the results are summarized in Table 3.

\begin{tabular}{|c|c|c|c|c|c|c|}
\hline Plasma Current & Data Points & $R^{2}$ & $\alpha$ & $\Delta \alpha$ & $\beta$ & $\Delta \beta$ \\
\hline$I_{P}=0.9 / 1.0 M A$ & 338 & 0.91 & 2.02 & \pm 0.05 & 1.29 & \pm 0.03 \\
$I_{P}=1.4 / 1.6 M A$ & 338 & 0.97 & 2.29 & \pm 0.04 & 1.46 & \pm 0.02 \\
$I_{P}=1.8 / 2.0 M A$ & 202 & 0.97 & 2.02 & \pm 0.03 & 1.34 & \pm 0.04 \\
\hline
\end{tabular}

Table 3: Coefficients of the regression results are evaluated for each plasma current group. The role of $H_{n e}$ on the neutron emission is not altered by an absence of $I_{P}$. $S_{n} \propto P_{B}^{\alpha \pm \Delta \alpha} H_{n e}^{\beta \pm \Delta \beta}$ is used for each $I_{P}$ group.

Although the role of $H_{n e}$ is significant in determining the stored energy of ions and neutron emission, there are variations among the discharges with similar value of $H_{n e}$. Since the direct measurement of $H_{n e}$ is not available, the variation may be due to many other factors such as errors in $H_{n e}$ estimation, differences in time history of $H_{n e}$, the effect of MHD on ions (thermal and fast ions)[19], and/or other unknown transport mechanisms.

\section{Summary}

In summary, the neutral-beam fueling peaking factor $\left(H_{n e}\right)$ is determined by both the magnitude of the target electron density and its profile shape for the fixed engineering parameters of the heating-beam system and tokamak, such as beam size, beam energy, orientation, and plasma sizes. In this paper, it has been shown that the role of $H_{n e}$ is significant in determining the ion stored energy and D-D fusion neutron rate in beam-heated plasmas in TFTR. However, the electron strored energy is found to be insensitive to $H_{n e}$. 'The present study suggests that any realistic scalings based on geometric factors in beam-heated plasmas should take into acount the variations in $H_{n e}$. In addition, a better theoretical model for ine influence of $H_{n e}($ or $H(0))$ on 
confinement as a function of plasma species is needed in order to extend the results of the present investigations to other hating schemes.

\section{Acknowlegement}

The authors wish to thank the 'TFT'K staff who contributed to the completion of this work. One of the authors (H. Park) deeply appreciates special encouragement from Drs. N. Bretz, L.C. Johnson, J.S. Machuzak, K.M. McCuire, I). Meade, J.I). Strachan, and K.M. Young to finish this paper. He also wishes to thank Drs. Z. (hang, J. ('allen, and D). Mikkelson for illuminating discussions. 'This work was supported by U.S. DoE contract No. DE-AC(O2-76-('HO-3073. 


\section{References}

[1] Goldston R.J., Plasma Phys. 26, 87 (1984).

[2] Rebut, P.H., Lallia, P.P., Watkins, M.L., in Plasma Physics and Controlled Nuclear Fusion Research 1988 (Pro. 12th Int. Conf. Nice, 1988), Vol.2, IAEA, Vienna (1989) 191.

[3] Strachan, J.D., Bell, M.G., et al., Phys. Rev. Lett. 58 (1987) 1004.

[4] Park, H.K., Goldston, R.J., and Taylor, G., in Proceedings of the 4th international Symposium on Laser-Aided Plasma Diagnostics, (Fukuoka, Japan, Nov. 1989)

[5] Bell, M.G., Arunasalum, V., Barnes, C., et al. in Plasma Physics and Controlled Nuclear Fusion Research 1988 (Pro. 12th Int. Conf. Nice, 1988), Vol.1, IAEA, Vienna (1989) 27.

[6] Meade, D., Arunasalum, V., Barnes, C., et al. in Plasma Physics and Controlled Nuclear Fusion Research 1990 (Pro. 13th Int. Conf. Washington D.C., 1990) Vol.1, IAEA, Washington D.C., (1991) 9-26.

[7] Park, H.K., Barnes, C.W., Budny, R., et al., Nucl. Fusion 32 (1992) 1042.

[8] Barnett, C.F., Atomic data for fusion, ORNL-6086, Vol-1, Controlled Fusion Atomic Data C'enter, ORNL, (July, 1990)

[9] Janev, R.K., Boley', C.D., Post, D.E., Nucl. Fusion 29 (1989) 2125.

[10] Hawryluk, R.J., in Physics of Plasma Close to Thermonuclear Conditions (Proc. Cource Varenna, 1979), Vol. 1, CEC, Brussels (1980) 19.

[11] Ramsey, A., C. E. Bush, H. F. Dylla, et al., Nucl. Fusion 31 (1991) 1811. 
[12] Bell, M.G., Arunasalam, V., Bitter, M., et al., Plasma Phys. Controlled Fusion 28 (1986) 1392.

[13] Park, H.K., Plasma Phys. Controlled Fusion 31, 2035, (1989).

[14] Mansfield, D.K., Park, H.K., Johnson, L.C., et al., Appl. Optics, 15, 4469, (1987) Japan, Nov. 1989)

[15] Taylor, G., Efthimion, P.C., McCarthy, M.P., et al., Rev. Sci. Insrum. 57, 1974 (1986)

[16] Snipes, J.A., Terry, J.L., Marmar, E.S., et al. in proceedings of the 18th European Conference on Controlled Fusion and Plasma Heating, Berlin, 1991, Vol. 1, 42-45, EPS, 1991.

[17] Zarnstorff, M., Bateman, G., Batha, S., et al. Paper IAEA-CN-56/A-2-2 presented at the 14th Internation Conference on Plasma Physics and Controlled Nuclear Fusion Research (Wurzburg, Germany, 1992)

[18] Callen, J.D., Christiansen, J.P., Cordey, J.G., et al., Nucl. Fusion, 27, (1987) 1857

‥

[19] Chang, Z., Fredrickson, E.D., Callen, J.D., et al. to be published in proceedings of the 20th European Conference on Controlled Fusion and P lasma Heating, Lisbon, 1993, Vol. 1, 42-45, EPS, 1993.

[20] Jassby, D.L., Arunasalum, V., Barnes, C.,et al. Phys. of Fluids B3 (1991) 2308.

[21] Strachan, J.D., Bell, M.G., Bitter, M., et al. Princeton Plasma Physics Laboratory Report, PPPL-2858, (Oct.) 1992 
Figure 1 The ratio between the calculated and fitted $H_{n e}$ as a function of $\bar{n}_{\mathbf{e}}$ for a various $F_{n e}$ with a fixed plasma minor $\left(a_{O}=0.8 \mathrm{~m}\right)$ and major $\left(R_{O}=2.45\right.$ m) radii. $H_{n e}$ is calculated by the three different methods: 0 - using old taulation of atomic cross-section $\left(\sigma_{1}\right), \triangle$ - using $\sigma_{1}$ with the old MSI model, and $\square$ - using new tabulation of atomic cross-section $\left(\sigma_{2}\right)$. The evaluated coefficients are summarized in Table 1.

Figure 2 The temporal evolution of $H_{n e}$ based on Eq. 1 with other plasma parameters such as global stored energy $\left(W_{t o t}\right)$, stored energy of electrons $\left(W_{e}\right)$, and neutron emission $\left(S_{n}\right)$ for the same heating-beam power $\left(P_{B} \simeq 22 M W\right)$; thick - - "supershot" discharge at $I_{P}=1.4 M A$ and - - L-mode discharge at $I_{P}=2.0 \mathrm{MA}$. Average $H_{n e}$ value of the supershot is an order of magnitude higher than that of L-mode for the first half second.

Figure 3 The level of inter-correlation between the chosen independent parameters is illustrated. (a) Heating-beam power $\left(P_{B}\right)$ used in the experiment for each plasma current is illustrated. (b) The achieved $H_{n e}$ is shown as a function of plasma current. (c) The achieved $H_{n e}$ for an applied $P_{B}$ is shown.

Figure 4 The ratio of the ion stored energy to the global stored energy as a function of $P_{B} H_{n e}$ is illiustrated; As $P_{B} H_{n e}$ is increased up to $25 \mathrm{MW}, W_{i} / W_{\text {tot }}$ is rapidly improved. Above this value, the ratio is saturated $\left(W_{i} / W_{\text {tot }} \simeq 0.7\right)$.

Figure 5 (a) The stored energy of ion is depicted as a function of $P_{B}$. For a fixed $P_{B}$, various value of the stored energy is obtained. (b) The stored energy of ion is fitted to the regression result shown in Eq. 3 . Note that $\boldsymbol{W}_{i}$ is linearly proportional to the central heating-beam fueling $\left(P_{B} H_{n e}\right.$ and $I_{P}$ is not a significant factor.

Figure 6 The D-D fusion neutron emission $\left(S_{n}\right)$ is fitted to the regression result shown in Eq. 5. $S_{n}$ is independent of plasma current. 


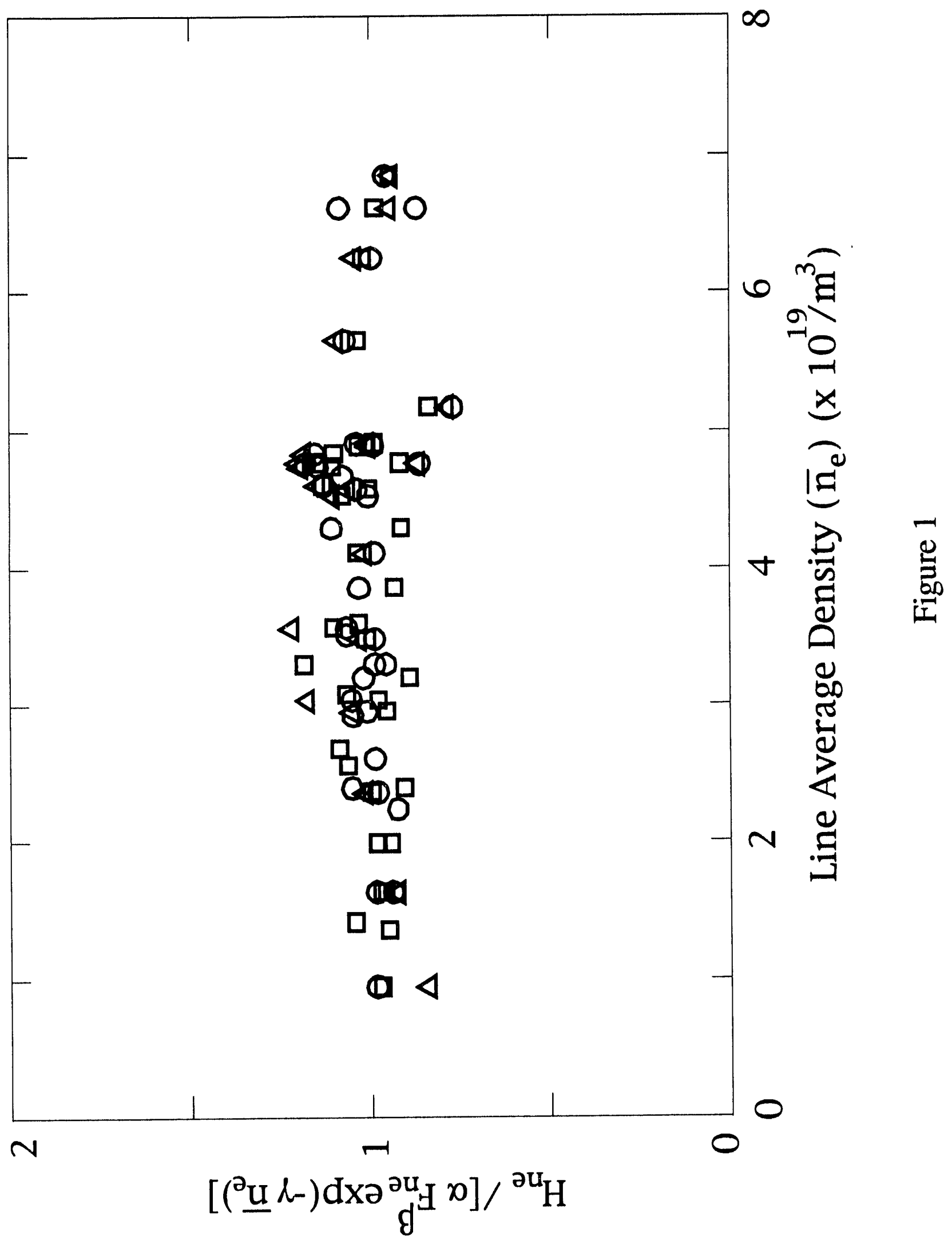



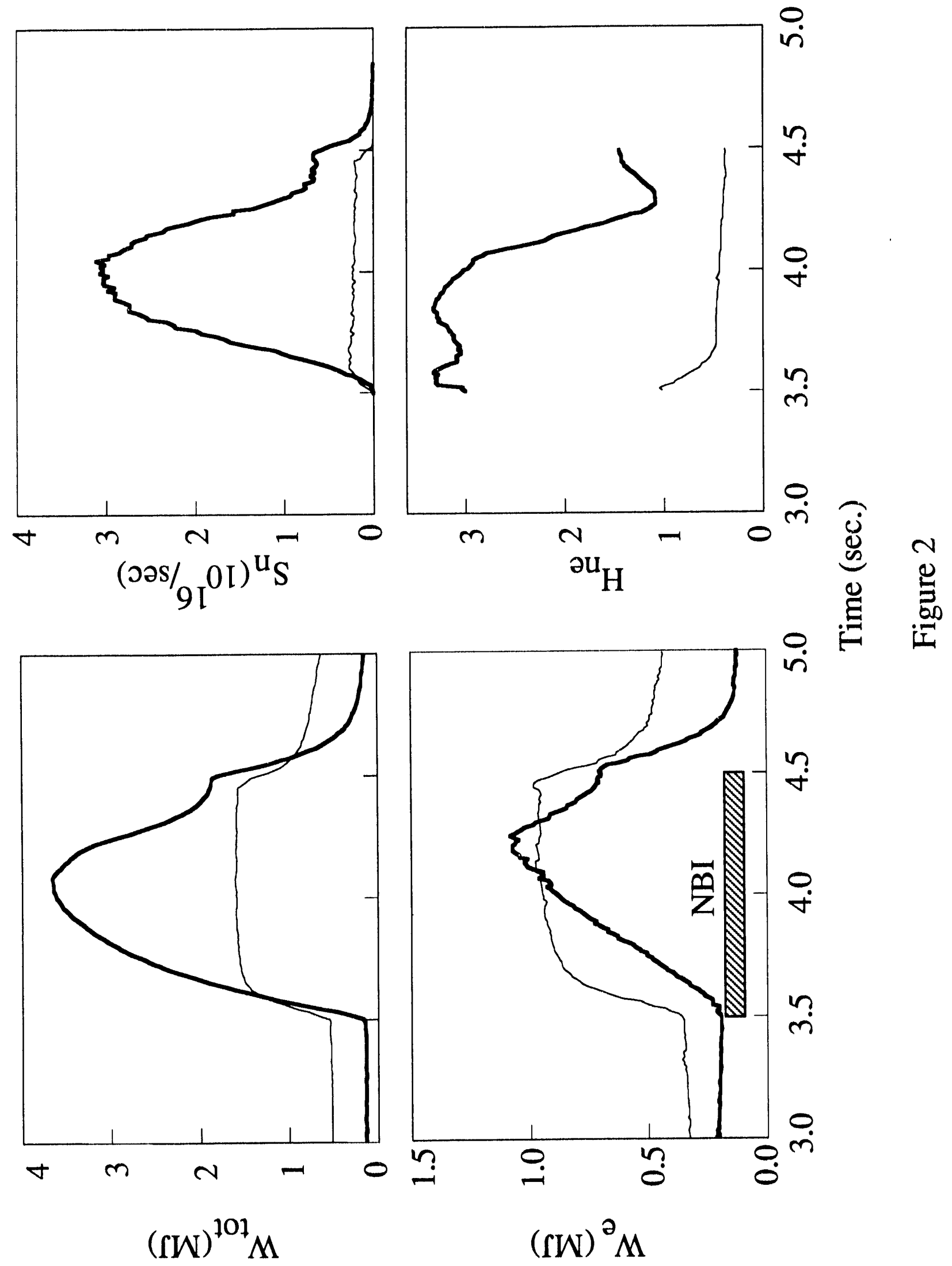

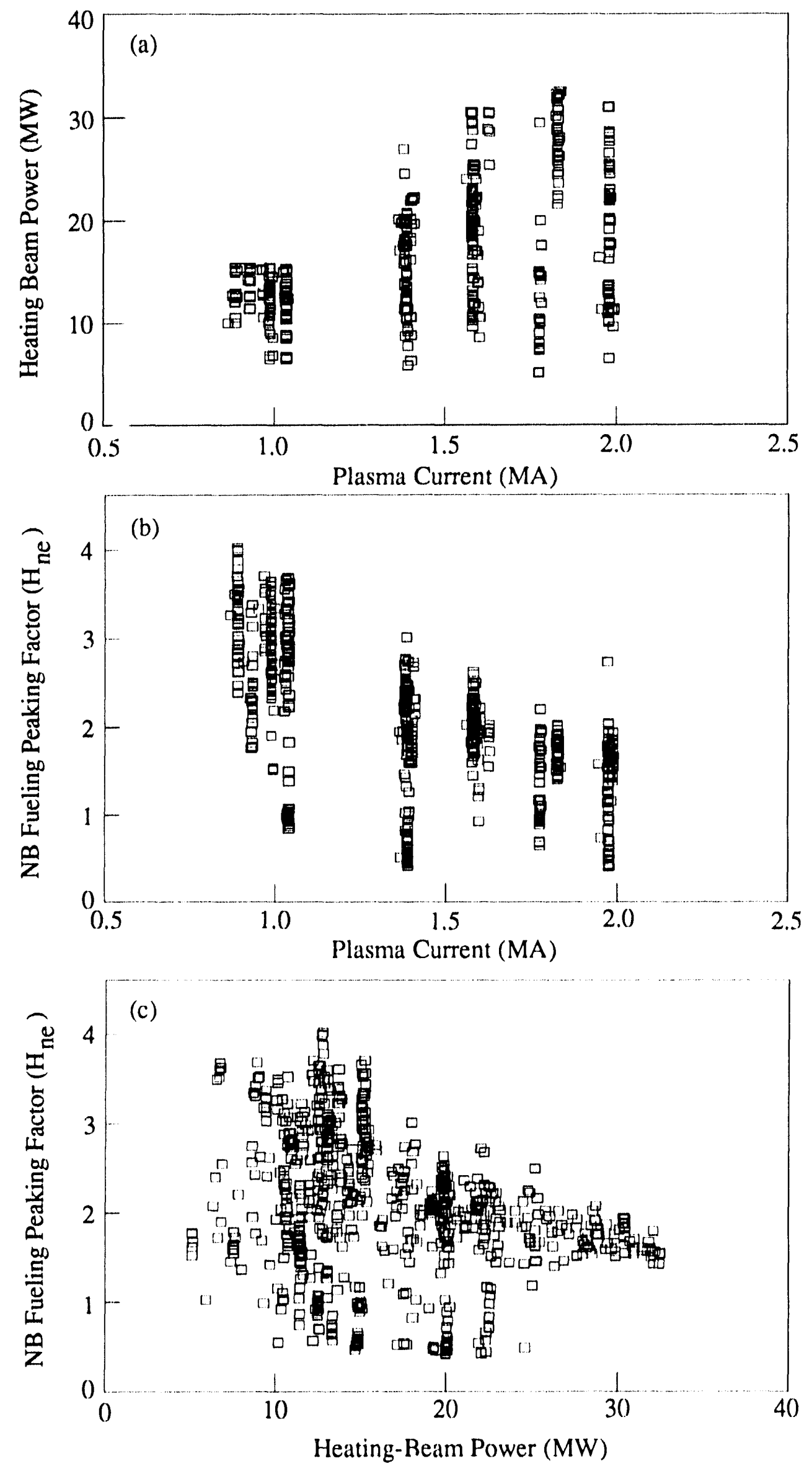

Figure 3 


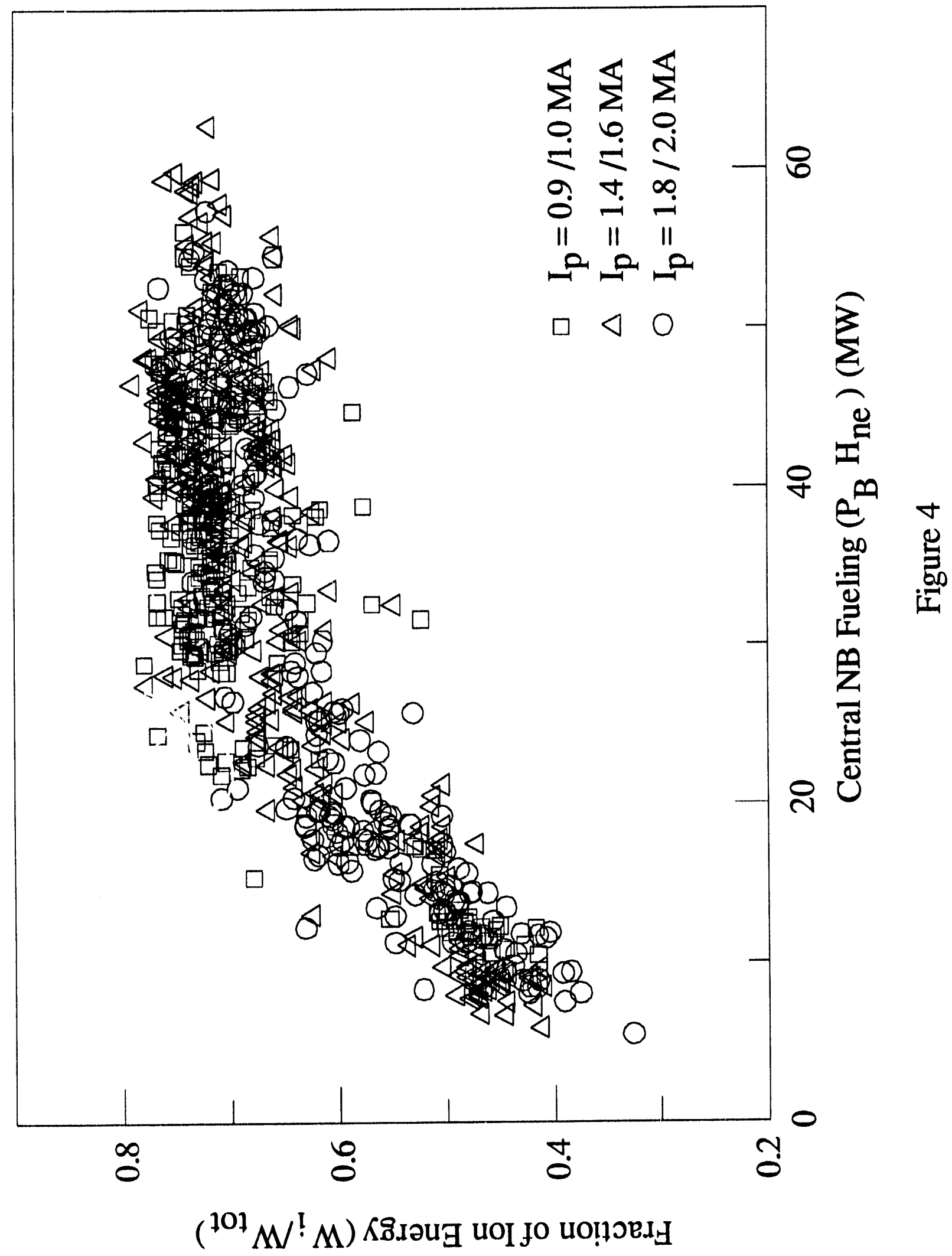


(a)

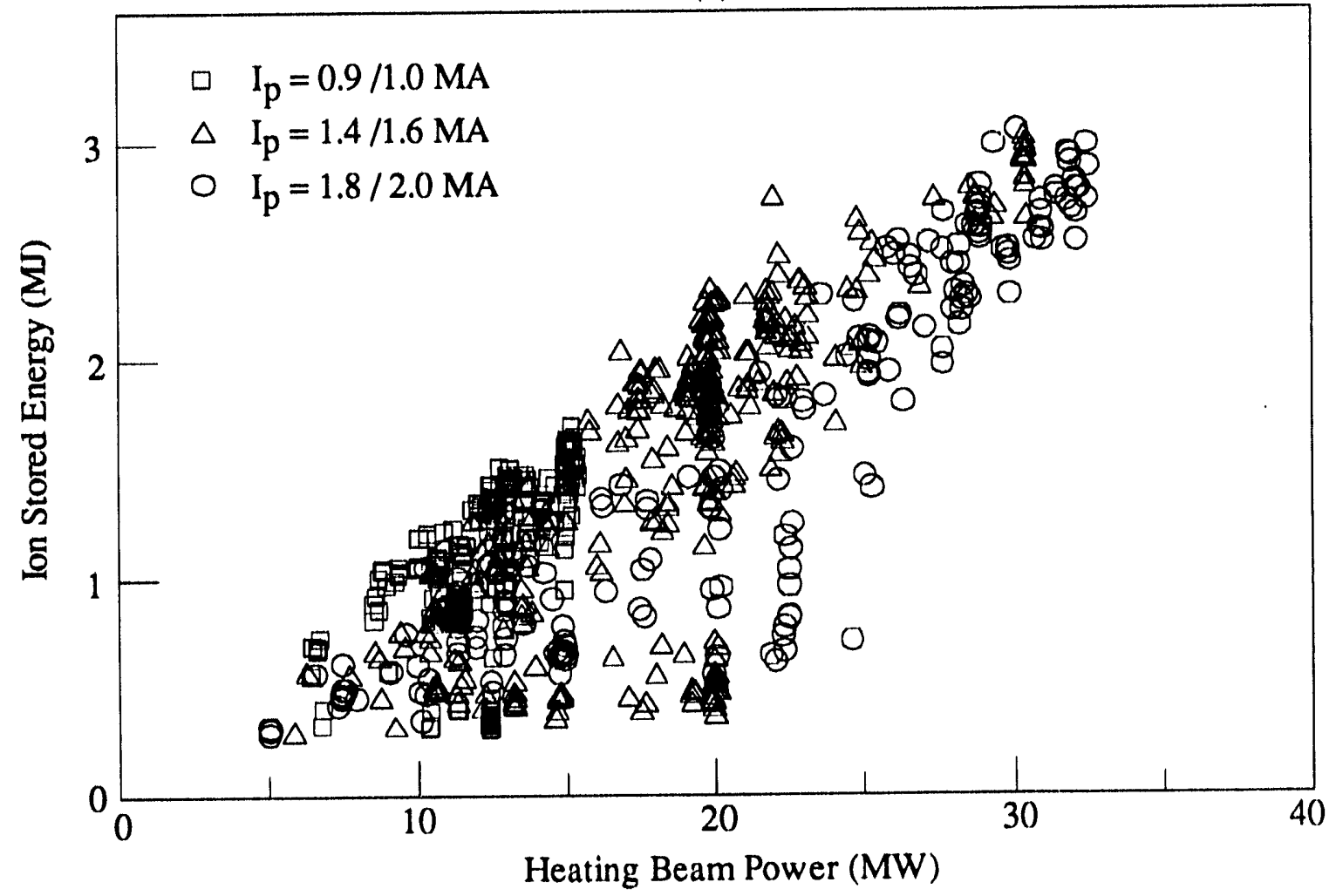

(b)

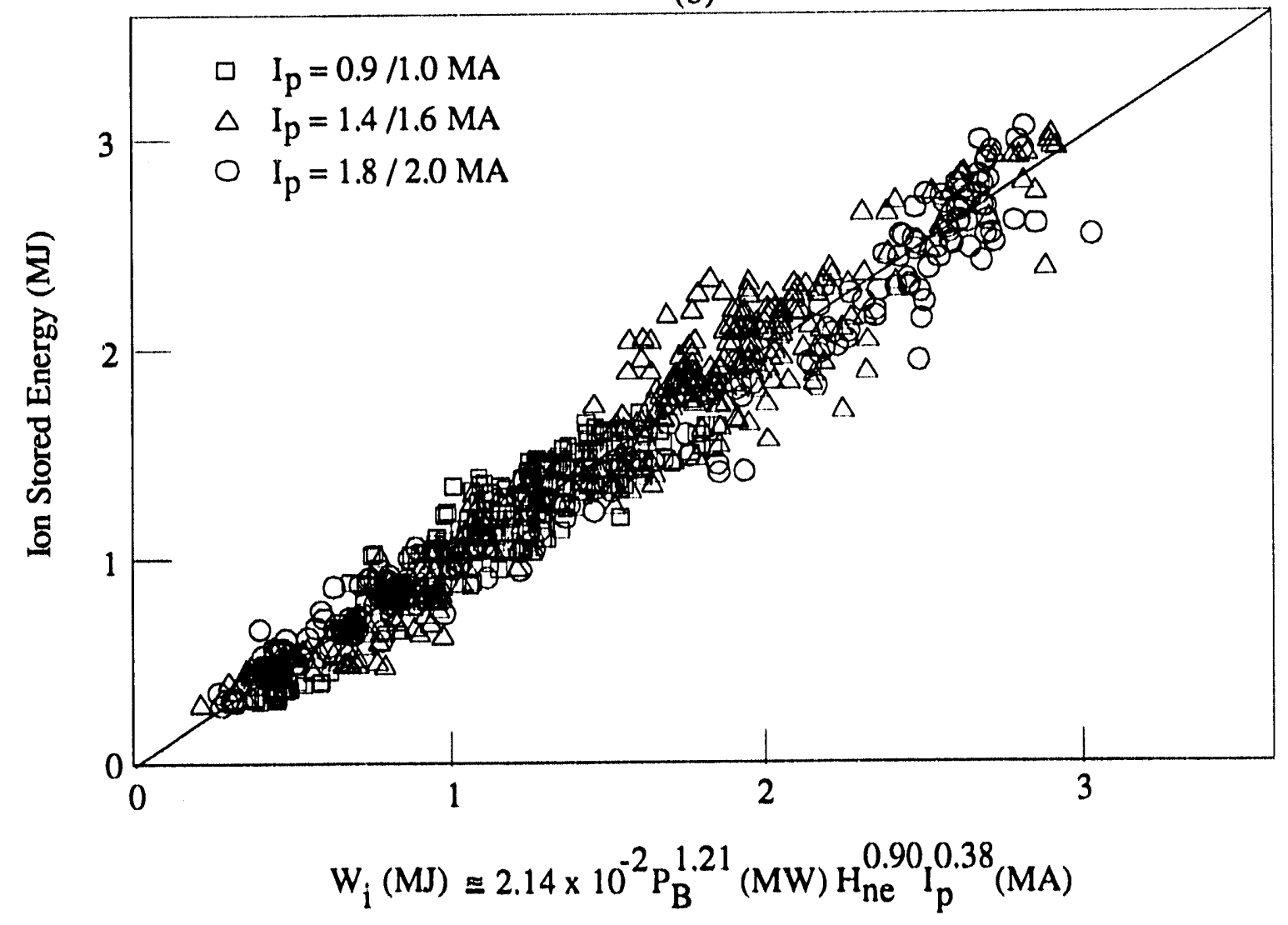

Figure 5 


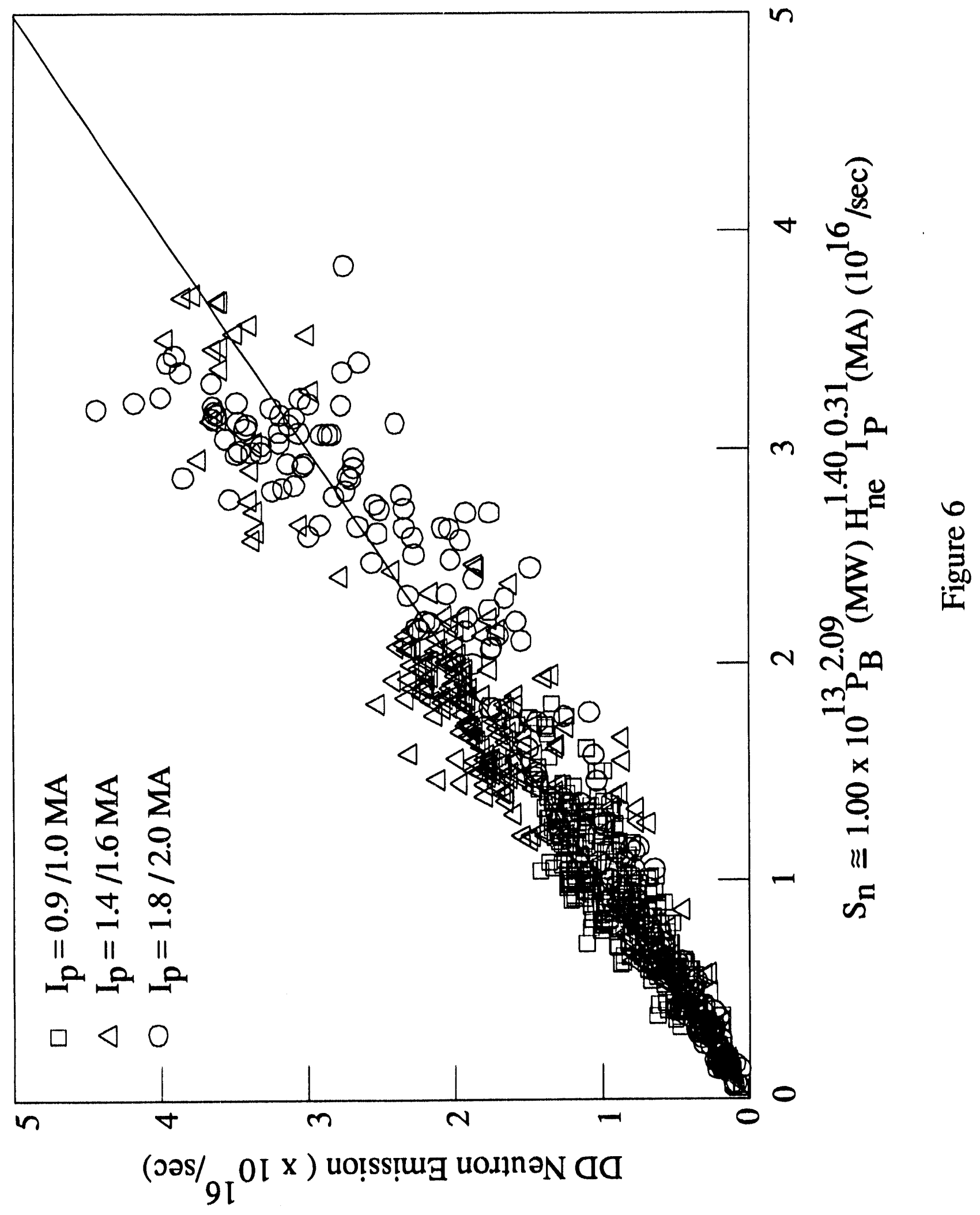


Dr. F. Peoloni, Univ. of Wollongong, AUSTRALIA

Prof. M.H. Brennan, Univ. of Sydnoy, AUSTRALIA

Plasma Rosearch Lob., Australian Nat. Univ., AUSTRALIA

Prol. I.R. Jones, Flinders Univ, AUSTRALIA

Prol. F. Cap, Inst. for Theoretical Physics, AUSTRIA

Prol. M. Hoindier, Instifut for Theoretische Physik, AUSTRIA

Prof. M. Gooseons, Astronomiect Instiwut, BELGIUM

Ecole Roydo Nilivire, Leb. de Phy. Plaemas, BELGIUM

Commisaion-Europeen, DG. XII-Fusion Prog., BELGIUM

Prof. R. Bouciqus, Rijkeuniveribit Gent, BELGIUM

Dr. P.H. Sakanaka, Instivito Fiaca, BRMZIL

Instituto Necional Do Posquieas Espadeit-INPE, BRUZIL

Documents Orfice, Abomic Eneroy of Cenada Ld., CANADA

Dr. M.P. Bechynek, MPB Technologies, Inc., CANADA

Dr. H.M. Skareand, Univ. of Sackatchowen, CANADA

Prof. J. Teictunam, Univ, of Montreal, CANADA

Prof. S.R. Sreentvasen, Univ. of Celgary, CANADA

Prol. T.W. Johnston, INRS-Energio, CANADA

Dr. R. Bolton, Contre canadion de husion meanstique, CANADA

Dr. C.R. James., Univ. of Aberta, CANADA

Dr. P. Lukdic, Komoneketho Univorszite, CZECHO-SLOVAKIA

The Lubrerian, Culham Leboratory, ENGLAND

Librery, P61, Authertord Appleton Laboratory, ENGLAND

Ars. S.A. Hulchinson, JET Librey, ENGLAND

Dr. S.C. Shame, Univ, of South Pectilic, FIJI ISLANDS

P. Mahonen, Univ. of Helsinivi, FINLAND

Prot. M.N. Busesc, Ecolo Polytochnique, FRANCE

C. Mouttor, Lab. Physique dos Milioux lonieds, FRANCE

J. Radot, CENMCADARACHE - Bat 506, FRANCE

Prot. E. Economou, Univ. of Crete, GREECE

Ms. C. Rinni, Univ. of loannina, GREECE

Dr. T. Mid, Acadomy Bibllographic Ser., HONG KONG

Preprint Librery, Hungarian Academy of Sci., HUNGARY

Dr. B. Descupte, Saha Inst. of Nucdeer Physics, INDIA

Dr. P. Kaw, Inst. for Plasma Research, INDIA

Dr. P. Rocenau, lereed Inet of Technology, ISPAEL

Librerien, Internationd Center for Theo Physics, ITALY

Miss C. De Palo, Ascociaziono EURATOM-ENEA, ITALY

Dr. G. Groses, Istituto of Ficican del Plasma, ITALY

Prol. G. Rostangni, Iettuto Gas lonizzati Dol Cnr, ITALY

Dr. H. Yamato, Tochiba Ros Dovel Center, JAPAN
Prof. I. Kawakami, Hiroshima Univ., JAPAN

Prof. K. Nishikawa, Hiroshima Univ., JAPAN

Director, Japen Alomic Energy Rosearch Inst., JAPAN

Prot. S. Itoh, Kyushu Univ., JAPAN

Research into. Ctr., National Instit. for Fusion Science, JAPAN

Prof. S. Tenaka, Kyolo Univ., JAPAN

Librery, Kyolo Univ., JAPAN

Prof. N. Inows, Univ. of Tokyo, LAPAN

Socrotary, Plasma Section, Eloctrobchnical Lab., JAPAN

S. Mori, Tectinical Advieor, MAERI, JAPAN

Dr. O. Niterai, Kumamoto Inst of Technology. JAPAN

J. Ayeon-Sook, Koren Alomic Energy Research Inst., KOREA

D.I. Chal, The Korea Adv, Inst of Sal. Tech., KOREA

Prol. B.S. Llay, Univ. of Welkato, NEW ZEALAND

Inst of Physica, Chinese Acad SC PEOPLE'S REP. OF CHINA

Librery, Inst of Plasma Physics, PEOPLE'S REP. OF CHI, 'a

Tringhua Univ. Lbrary, PEOPLE'S REPUBLIC OF CHINA

2. U, S.W. Int Physics, PEOPLE'S REPUBLIC OF CHINA

Prot. J.A.C. Cebred, Instibito Superior Tecnico, PORTUGAL

Dr. 2. Potrus, Al I Cuza Univ., Romania

Dr. J. do Viliers, Fusion Studies, AEC, S. AFAICA

Prof. M.A. Hellberg, Univ. of Natal, S. AFRICA

Prot. D.E. Km, Pohang Inst. of Sa. \& Tech., SO. KOREA

Prof. C.I.E.M.A.T, Fusion Division Ubrary, SPAIN

Dr. L SEnfio, Univ. of UMEA, SWEDEN

Librery, Royd Inst. of Tectnology, SWEDEN

Prot. H. Whatmeon, Chamers Univ, of Tech., SWEDEN

Contro Phys. Des Plasmas, Ecolo Polytech, SWITZERLAND

Bibliotheek, Inst. Voor Plasma-Fysica, THE NETHERLANDS

Asst. Prot. Dr. S. Cakir, Middo East Tech. Univ., TURKEY

Dr. V.A. Gubtikh,Sat. Res. Inst. Eloctrophys.I Apparatus, USSR

Dr. D.D. Ayubv, Siborian Brench of Academy of Sol., USSA

Dr. G.A. Eliecev, I.V. Kurchatov Inst, USSR

Lborerien. The Ukr.SSA Academy of Sciances, USSR

Dr. L.M. Kovrizhnykh, Inst. of Genord Physics, USSR

Korntorectungeaniego $\mathrm{GmbH}$, Zentrabibliothok, W. GERMANY

Bibliothok, Inst. For Plasmatorecting. W. GERMANY

Prot. K. Schinder, Ruhr.Univereitt Bochum, W. GERMANY

Dr. F. Wogner, (ASDEX), Max-Planck-Institul, W. GERMANY

Lborerien, Max.Planck-Institut, W. GERMANY

Prof. R.K. Janev, Inst of Physios, YUGOSLAVIA 

